\title{
CONCEPTUAL SITE MODEL: AN INTERMEDIARY BETWEEN BASELINE STUDY AND RISK ASSESSMENT
}

\author{
TALIB E. BUTT ${ }^{1}$, HINA AKRAM ${ }^{2,3}$, CHARFELDINE MAHAMMEDI $^{4} \&$ CHRISTOPHER HOUSE $^{5}$ \\ ${ }^{1}$ Faculty of Engineering and Environment, Northumbria University, UK \\ ${ }^{2}$ Department of Life Science, University of the Punjab, Pakistan \\ ${ }^{3}$ Department of Life Sciences, Minhaj University, Pakistan \\ ${ }^{4}$ Centre for Architecture and Built Environment Research (CABER), University of the West of England, UK \\ ${ }^{5}$ University of Wales Trinity Saint David (UWTSD), UK
}

\begin{abstract}
A baseline study is a means of and for acquiring, organising, cleansing, presenting, and analysing all the data and/or information of preliminary investigation for hazard and risk assessment. This output of baseline study can be regarded as a conceptual site model (CSM), which has wide-ranging aspects that the literature to date does not appear to have captured a detailed account of, thereby limiting the full exploitation of CSM capacity in environmental communication between varying stakeholders. This knowledge-gap is focused upon by bringing out some new insights regarding CSM and creating an account of features of CSM for the first time. To start with, this study introduces CSM as an "intermediary" between a baseline study and the follow-on stages of the associated environmental risk assessment, and this is an innovative idea in its own right. Furthermore, light is torched upon CSM in several other new ways to show how CSM can serve as a live and "organic" foundation of an environmental risk assessment. It is depicted how the eight modules of a baseline study - geology, hydrology, hydrogeology, meteorology, geography, topography, anthropology and site management can inform to develop a CSM. Also, a CSM could be descriptive and/or schematic which could still be computer-aided or non-computer aided. Another implication is that even though CSM contains the word "site" in the phrase, it does not mean that the model includes only the geographical or physical extent of the site, rather it also includes off-site, i.e., site-surroundings. This is where the aforesaid eight modules can cover both on-site and off-site characteristics of a given site being assessed. The innovative account of CSM parameters, advantages and uses would pave the way for further research and ignite debates among a diverse range of researchers, consultants, environmental regulators, decision-makers and other stakeholders.
\end{abstract}

Keywords: conceptual site model, risk assessment, risk analysis, baseline study, site characterization, site information.

\section{INTRODUCTION}

Environmental hazards are increasingly posing threats to living organisms, ecology and human health due to emissions, wastes, effluents, resources depletion and alike which come directly and indirectly from anthropogenic activities. Risk assessment and management approaches are increasingly being applied to combat such hazards. However, current approaches for environmental risk assessment lack in integration [1]-[4]. Baseline study, being the foundation of risk analysis, can play a critical role [5]. This is because a holistic baseline study can establish a course of action on acquiring, sorting, presenting, cleansing, and analysing all the data and/or information of initial investigation of a given scenario and could be systematically related to the subsequent stages of the risk assessment [6]. To link baseline study with follow-on stages of risk assessment, conceptual site model (CSM) can be an effective means, not only in terms of format and presentation but also the content. Regardless of a CSM being computer aided or non-computer aided, it acts as a backbone which runs from baseline study into the rest of the risk assessment process. 
CSM is interpretation of available information at any point in time and a primary vehicle for communicating technical data which comes from the baseline. CSM includes general information but still specific to a given site. This involves information relevant to site operations and past investigations; site characteristics include a wide range of information related to geology, hydrogeology, and meteorology, actual or potential receptors and contaminant source characteristics [7]. This study also draws upon characteristics of areas in the surrounding of a given contaminated site to frame a CSM that covers both on-site and off-site. CSM can assist, for example, to establish whether there is a likelihood of imminent and substantial endangerment; justify characterization approaches; and prioritize investigation and remedial resources [8]. A diverse and wide variety of stakeholders would also benefit from using CSM as a primary organization and communication tool. CSM can be used to help justify what information is essential for successful management of actual and potential risks. Implications of CMS in relation to baseline study and risk assessment are at the core of this study.

\section{PROBLEM STATEMENT}

Baseline can render a risk assessment more holistic, integrated and systemic. However, to date limited research has been conducted on the parameters and requirements of baseline study particularly in the context of in what manner, why, and what information is to be collated in order to render risk analysis more appropriate, integrated and complete. This is where CSM can be a useful mechanism not only to collate but also shape outputs of a baseline study, and categorically, systematically, sequentially and correspondingly relate with different parts and stages of the risk assessment process. In other words, CSM can bring baseline study and the rest of the risk assessment process on the same page in a seamless manner. However, in this specific context the relationship between baseline study and risk assessment, CSM has not been much studied. The potential of CSM has not been fully realized both conceptually and practically in terms of how it can be a platform or hub of information via which effective environmental communication can take place between a wide-ranging stakeholders coming from both technical and non-technical backgrounds and interests. This is the knowledge-gap that is focus of this study.

\section{RESEARCH AIM AND METHODOLOGY}

The aim of this study is to signify CSM as an intermediary between baseline study and follow-on stages of risk assessment, thereby creating an account of innovative ideas and new insights on CSM. The idea is how to widen the understanding and thereby unlock more potential benefits of CSM to improve environmental as well as risk communications. Given the brevity of the paper, only a few key steps of the research methodology are listed below:

- The first step is to create an account of all elements and sub elements of risk assessment at various stages from start to end. These factors are traced out from pre-existing knowledge of risk assessment approaches by systematic review of literature.

- Establish the state-of-the-art by gathering and categorizing all these components in a logical order and produce a matrix of existing knowledge. Knowledge gaps are identified covering all factors and sub factors of risk assessment.

- Outline a framework which accounts for baseline study and risk assessment in connection to CSM.

- In the course of developing the framework, it is especially illustrated that outputs and inputs of baseline study and risk analysis can be connected via CSM. 


\section{LITERATURE REVIEW}

\subsection{Environmental risk assessment}

A good environment site assessment will present a considerable information to identify potential or existing environmental constraint to be designed for the site and is likely to reduce problems and conflicts later. Thoroughly evaluating environmental constraints and associated requirements and regulations is essential to any successful land-use plan [9]. The level of detail that will be necessary for site appraisal will vary depending on the scale of the proposal and the characteristics of the site [8]. Environmental site assessment has become an important component of real estate transactions, especially for commercial and industrial property. In fact, in the case of private development, understanding environmental constraints and the cost and feasibility of potential mitigation is key to understanding the true value of real property and whether a project will "pencil out".

In the United States environmental site assessment (ESA) criteria were originally developed by organizations that focused, almost exclusively, on surface, subsurface, and pollution source contamination [10]. The purpose of Environment Site Assessment is to gather sufficient information to develop an independent professional opinion about the environment condition of the property and to identify actual or potential environmental contamination [11]. Furthermore, the ESA report is prepared to identify potential or existing environmental contamination; the report analysis typically addresses contaminated land. The contamination land is considered as the main component of ESA in United states, while other site assessment takes into consideration many constraints such as water pollution, environment noises, air pollution, groundwater, traffic, geotechnical. etc.

In the United Kingdom, the environmental assessment is well established planning procedure, has been formally introduced under the Town and Country Planning (Assessment of Environmental Effects) Regulations in 1988 [12]. Literature review shows reports and Councils in United Kingdom assess the environment constraint which could affect the site development. While some reports share similar views on certain environment constraint, some views differ completely (Table 1). The aim of the reports is to determine the feasibility study through the identification of the overall baseline environmental site conditions with the potential environmental constraints related to the proposed project to inform the design process.

Table 1: The main environmental constraints.

\begin{tabular}{|l|c|c|c|c|c|c|}
\hline Environmental constraints & \multicolumn{7}{|c|}{ Reports } \\
\hline & {$[13]$} & {$[14]$} & {$[15]$} & {$[16]$} & {$[17]$} & {$[18]$} \\
\hline Air quality & $\checkmark$ & $\checkmark$ & & & & \\
\hline Culture heritage & $\checkmark$ & & $\checkmark$ & $\checkmark$ & $\checkmark$ & \\
\hline Travel management & $\checkmark$ & & $\checkmark$ & & $\checkmark$ & $\checkmark$ \\
\hline Noise & $\checkmark$ & $\checkmark$ & $\checkmark$ & & & \\
\hline Flood risk & & $\checkmark$ & & & $\checkmark$ & $\checkmark$ \\
\hline Water pollution & & & $\checkmark$ & & $\checkmark$ & $\checkmark$ \\
\hline Light pollution & & $\checkmark$ & & & & \\
\hline Contaminated land & $\checkmark$ & $\checkmark$ & & $\checkmark$ & $\checkmark$ & $\checkmark$ \\
\hline Waste & & & $\checkmark$ & & $\checkmark$ & \\
\hline
\end{tabular}




\subsection{Baseline study in relation to environmental risk assessment}

The review of the environment-related literature shows that baseline study is a crucial and primary factor in an environmental risk assessment [19], [20]. There are a number of elements that are needed to be integrated to form a holistic framework of the baseline study to support risk assessments more effectively. The information can be categorised into eight modules as follows: (1) geology; (2) hydrology; (3) hydrogeology; (4) topography; (5) meteorology; (6) geography; (7) site management; and (8) human influences [21]. Current baseline study approaches for risk assessments are found not to have included all of these eight aspects in an integrated manner. A comprehensive review of risk assessments currently used for environmental management highlights clearly that there is currently a lack of an integrated procedure for carrying out baseline study in various environmental fields.

\subsection{The state-of-the-art of conceptual site models (CSM)}

CSM is among the tools that are available to managers to understand the complex physical, ecological and contamination conditions of their sites within the context of current and future land uses. In addition, conceptual site models are an essential element of the assessment and present the possible connections between identified potential contaminant sources, pathways and receptors [7]. Burger et al. [22] indicate that CSMs are graphic depictions of exposure conditions on a contaminated site illustrating sources, hazards, environmental transport, pathways and exposure routes and receptors. However, a well-defined, detailed CSM will help the team identify data necessary to support decisions about the property.

Developing a CSM is a critical step in evaluating a contaminated site and must be prepared during the initial stage of the clean-up process, the site characterization phase. Further, CSMs can provide regulators, managers, and the public with a clear depiction of the major ecological resources at risk in the ecosystem, rather than the receptor-by-receptor approach normally taken. CSMs provide the "big picture" in a simple graphic.

In fact, it is essential to be able to benefit from available CSM tools by exploring existing knowledge and experience surrounding the issues being investigated. Many lessons can be learned; much knowledge and understanding can be gained through analysing how these CSMs have been developed, what their contributions are, and how they are validated and disseminated to users. With this in mind, Table 2 presents a number of CSM formats. The format of presentation will be dictated by the complexity of the site and the amount and type of data that are available.

Table 2 reveals that CSM is developed in order to establish the pollutant linkage between Source-Pathway-Receptor either by computer-aided tool or by non-computer aided. There is no evidence that CSM is developed to establish the environmental risk assessment at the baseline study stage. This gap has been identified and well reflected in Fig. 1.

\section{SIGNIFICANCE}

The presentation of this research shows that CSM is primarily used as a means to link sources, migration pathways and ecological receptors as well as the circumstances under which exposure is anticipated in environmental communication. Need of CSM at baseline study level for in-site as well as off-site together with follow on stages of risk assessment has not been considered as this research presents. Finally, knowledge gaps are not only identified but recommendations are also framed for what and how innovative building blocks of new knowledge can be created to overcome the identified knowledge gaps, so as to get benefits from CSM to best portray available information in multiple dimensions to inform and help 
Table 2: Types of conceptual site model.

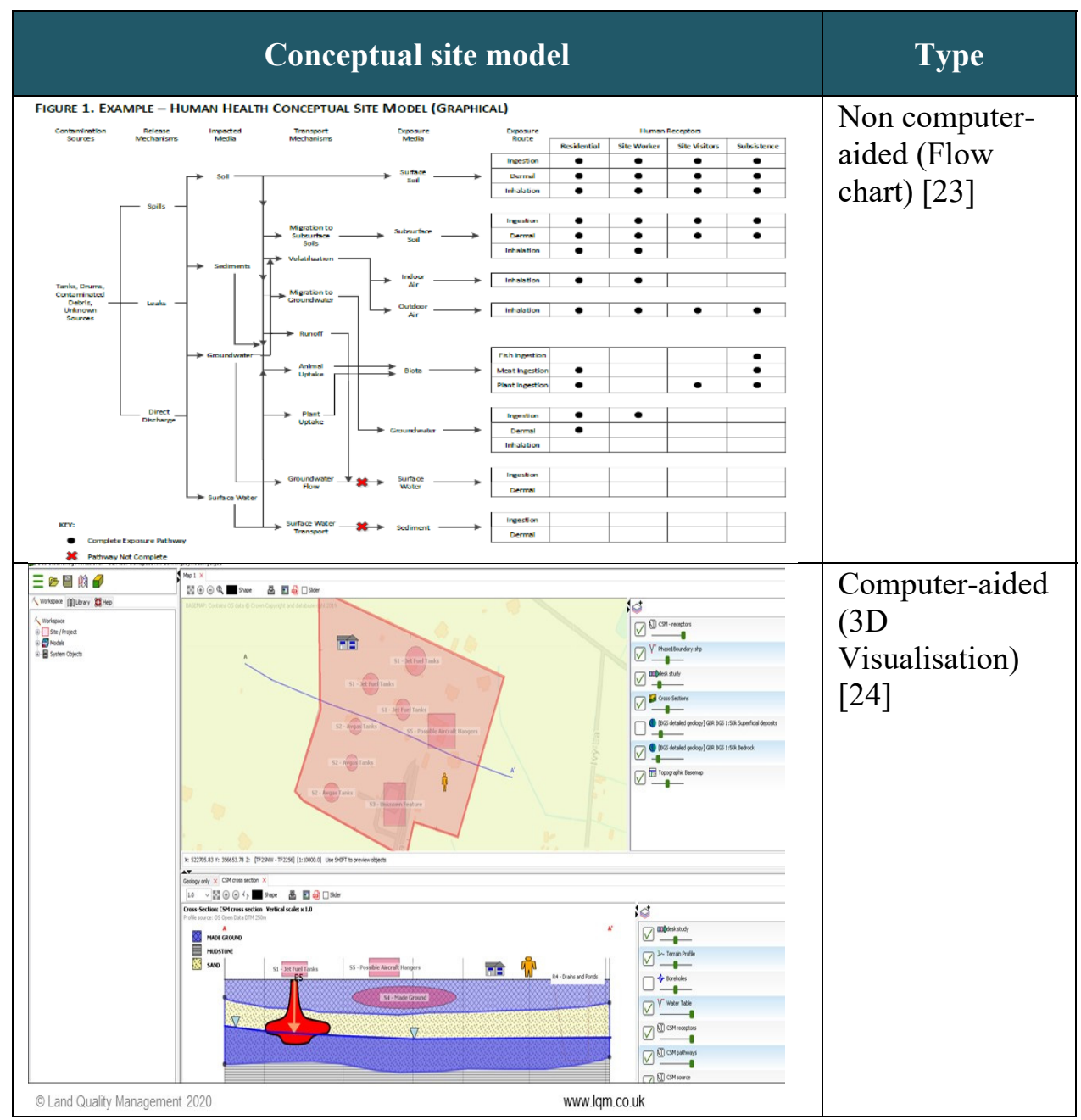

wide range of consultants, environmental regulators, decision-makers, construction industry and other stakeholders. This can be clearly observed in Fig. 1.

\section{CONCLUSIONS AND RECOMMENDATIONS}

Environmental risk assessment is increasingly being applied to combat environmental hazards and it is also obtaining a position in environmental legislation in different countries around the globe. Furthermore, for a successful environmental risk assessment, a correspondingly successful baseline study is required for it is the foundation of any risk assessment exercise. This study has signified that the CSM is an intermediary between the two entities - risk assessment and baseline study. CSM can help in relating the two more categorically, systematically, systemically, sequentially and correspondingly, so that, not only data and information can be transferred between the two as and when needed, but also 


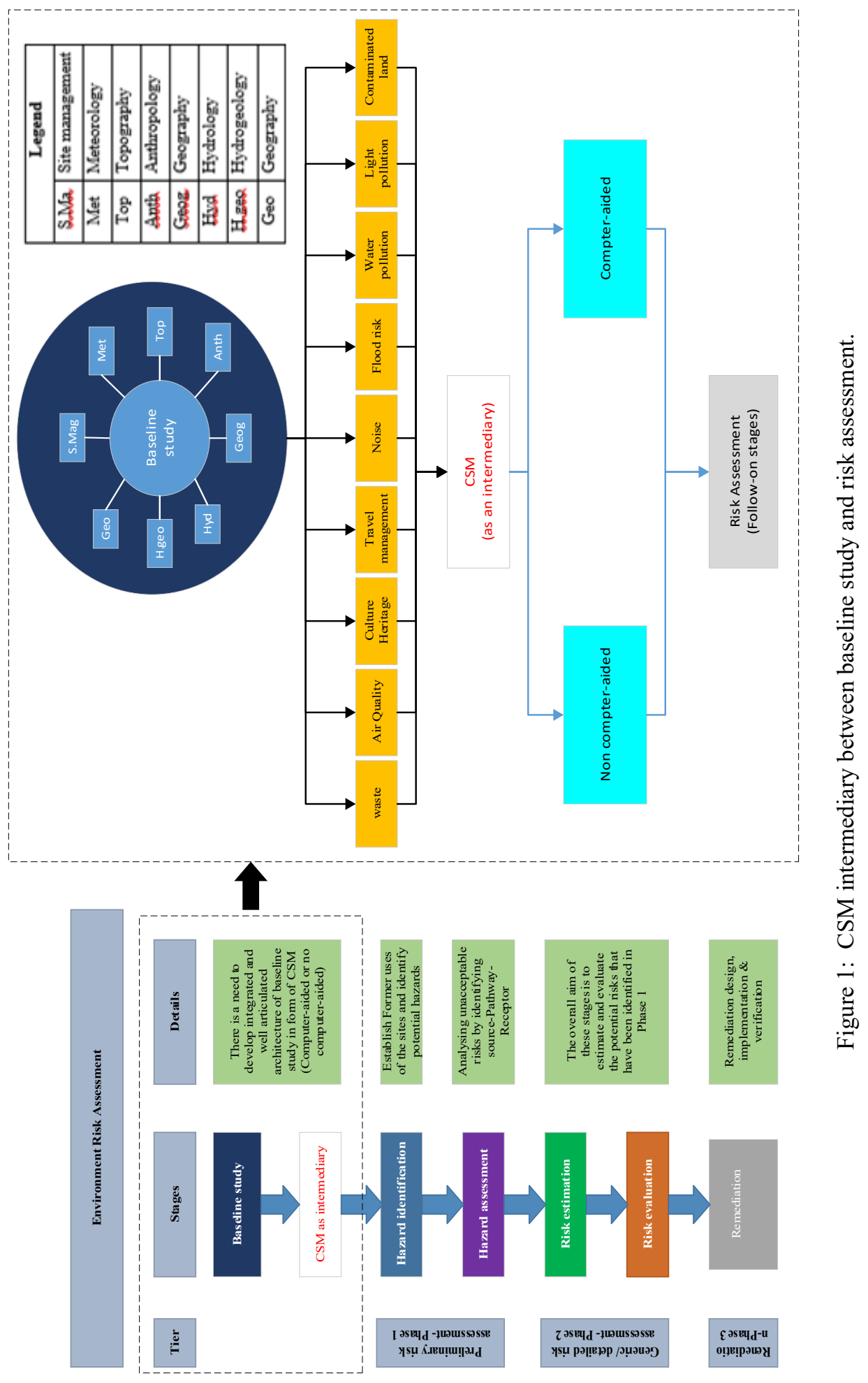


assist in collating, shaping and prioritising the data and information; let alone the benefits that CSM can bring about to enhance environmental communication and risk communication between wide-ranging stakeholders coming from both technical and non-technical backgrounds. These include environmental consultants, environmental regulators and legislators, planning authorities, local councils, many other business fields and disciplines (even including a general member of the public). Other advantages that CSM can bring are transparency, traceability and simplicity for interested and concerned parties as CSM can be a platform and hub of data and information between them all.

CSM can be represented with schematics, although at times it may well be in the form of text and numeric, or any combination of the three depending on how detailed it is appropriate to be and how many iterations it has been through. Additionally, computer aided approaches can also be used to present CSM. Digital engineering such as BIM (Building Information Modelling) are computer-aid approaches which can be the future of CSM and this is where further studies and research can be carried out. The paper establishes that in line with baseline study and risk assessment, CSM would have to be equally, correspondingly multi- and interdisciplinary. This is yet another area of study on how the multi- and inter-disciplinarily facet of CSM can be enhanced by integrating geology, hydrology, hydrogeology, topography, meteorology, anthropology, geography and site management and even climate change and sustainability. The approach presented in the paper for CSM itself is conceptual, i.e., currently an idea, which needs to be further developed in practical sense in future. Probably, this is where BIM approaches can be used to integrate different disciplines as appropriate in the form of an e-CSM (i.e., electronic or digital CSM) which would be inter-active, hyperactive and yet "live", thereby rendering CSM as an "organic" platform of representation for a given site being assessed and managed. BIM approach can also help to filter data and information of CSM as appropriate for a concerned and interested stakeholder/party. Finally, CSM can save specially non-experts in risk assessment from putting time and effort in trying to comprehend the complexities of risk science, as they can merely communicate from, with and through CSM.

\section{REFERENCES}

[1] Butt, T.E., Lockley, E. \& Oduyemi, K.O.K., Risk assessment of landfill disposal sites: State of the art. Waste Management, 28(6), pp. 952-964, 2008.

[2] Butt, T.E., Gouda, H.M., Baloch, M.I., Paul, P., Javadi, A.A. \& Alam, A., Literature review of baseline study for risk analysis: The landfill leachate case. Environment International, 63, pp. 149-162, 2014.

[3] Butt, T.E., Javadi, A.A., Nunns, M.A. \& Beal, C.D., Development of a conceptual framework of holistic risk assessment: Landfill as a particular type of contaminated land. Science of the Total Environment, 569-570, pp. 815-829, 2016.

[4] Butt, T.E., Entwistle, J.A., Sagoo, A.S., Akram, H. \& Massacci, G., Combined risk assessment for landfill gas and leachate-informing contaminated land reclamation for appropriate construction projects. Proceedings Sardinia 2019 17th International Waste Management and Landfill Symposium, Margherita di Pula (Cagliari), Italy, CISA, 2019.

[5] Aqeel, M., Jamil, M. \& Yusoff, I., Soil contamination, risk assessment and remediation. Environmental Risk Assessment of Soil Contamination, ed. M.C. Hernandez-Soriano, IntechOpen, 2014.

[6] Rivett, M.O., Petts, J., Butler, B. \& Martin, I., Remediation of contaminated land and groundwater: Experience in England and Wales. Journal of Environmental Management, 65(3), pp. 251-268, 2002. 
[7] Environmental Agency, Guidance for the Safe Development of Housing on Land Affected by Contamination, Vol. 1, 2008.

[8] DEFRA, Environmental Agency, Model Procedures for the Management of Land Contamination, A Research Report Prepared by Casella Stanger under the Science Project SC02000028 for the UK Environment Agency, Bristol, 2004.

[9] Prasse, B., Addressing environmental constraints in development plans, 2012. http://info.esg.adec-innovations.com/blog/bid/222411/Addressing-EnvironmentalConstraints-in-Development-Plans. Accessed on: 16 Jun. 2020.

[10] Lange, J.H., Kaiser, G. \& Thomulka, K.W., Environmental site assessments and audits: Building inspection requirements. Environmental Management, 18(1), pp. 151-160, 1994.

[11] Feng, C. \& Chengtao, C., Application of phase I environment site assessment (ESA). Guangdong Chem. Ind., 10, p. 62, 2009.

[12] Glasson, J. \& Therivel, R., Introduction to Environmental Impact Assessment, 4th ed., Routledge: Oxford, 2012.

[13] West Sussex County Council, Lyminster Bypass Feasibility Study, Environmental Counstraints Report, West Sussex, 2012.

[14] City and County of Swansea, Pollution and Environmental Constraints, Swansea, 2013.

[15] Devon County Council, Devon Minerals Plan Summary of Site Appraisal Findings, Exeter, 2012.

[16] Axis, Manchester Airport Group Environmental Evidence Study Environmental Appraisal, Manchester, 2010.

[17] ESBI Environmental Group, Site Selection Review of Constraints, Dublin, 2011.

[18] Tunbridge Wells Borough, Development Constraints Study, Tunbridge Wells, 2016.

[19] Environment Agency, Hydrogeological risk assessments for landfill and the derivation of groundwater control and trigger levels, Bristol, 2003.

[20] Blight, G.E., Graded landfill requirements in South Africa: The climatic water balance classification. Waste Management Research, 24(5), pp. 482-490, 2006.

[21] Butt, T.E., Alam, A., Gouda, H.M., Paul, P. \& Mair, N., Baseline study and risk analysis of landfill leachate: Current state-of-the-science of computer aided approaches. Science of the Total Environment, 580, pp. 130-135, 2017.

[22] Burger, J., Mayer, H., Greenberg, M., Powers, C., Volz, C. \& Gochfeld, M., Conceptual site models as a tool in evaluating ecological health: The case of the Department of Energy's Amchitka Island nuclear test site. Journal of Toxicology and Environmental Health: Part A Current Issues, 69(13), pp. 1217-1238, 2006.

[23] Department of Environmental Conservation, A Tool for Developing an Ecological Conceptual Site Model, State of Alaska, 2017.

[24] Land Quality Management. Conceptual Site Models Groundhog Professional, 2015. www.lqm.co.uk/csm/. Accessed on: 17 Jun. 2020. 